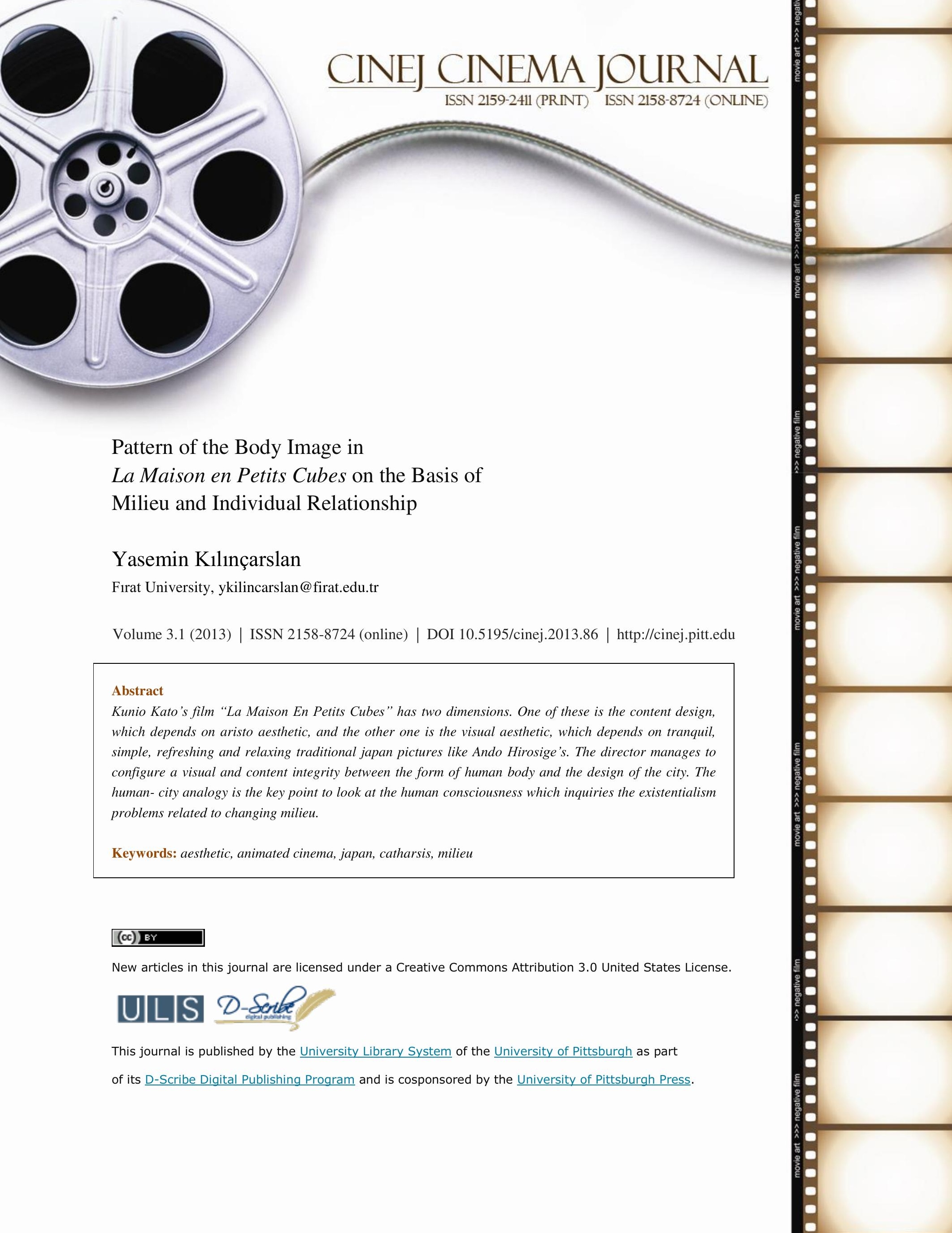


Pattern of the Body Image in La Maison en Petits Cubes

on the Basis of Milieu and Individual Relationship

\section{Yasemin Kilınçarslan}

\section{Introduction}

Kunio Kato's Film La Maison en Petits Cubes has a crucial importance in the information era of digital arts. Searching for freedom of picture along with formal values which is carried by its own genuine elements looks like creating an adventure of artist's own freedom without denying the common social life necessities. Hence, art gains a meaning by the efforts which aims to personal freedom of human, contrary to common lifestyles which blunt the free personal tendencies, and a standardizing process. In this film, the artist uses the classical narration techniques and the styles. It is an exceptional film for a director who lives in information era's constant bombardment as a member of the young generation. Kato constitutes extremely perfect story spin as content and form in this short animated film. The backbone of the film is shaped around the life of an old man, and this shaping process carries the humanistic emotions like a highway. According to Athens, there was an analogy between body and building. In the film this analogy exists between individual loneliness and the condition of the city which is left after the flood. As a kind of life aesthetic, the individual tries to overcome ecological disasters by the way of alternative life model which resists to nature oriented obstacles. Traces of past life experience of individual are parallel to the past of the city. The city and the building try to stand upright like the old man's body. The old man doesn't prefer to be outside of the city on contrary, he prefers the loneliness and estrangement and at the end he becomes a city-body.

\section{Footprints of Traditional Japanese Pictures in the Classical Japanese Animated Cinema}

At the present day, it can be seen that, popular media contents have been attracted of audiences like Japanese animated cinema. In this point, special concepts of Japanese animated cinema should be addressed. These concepts are "Otaku" "Manga" and "Kawaii". Otaku and Manga artifacts are generally related to subcultural behaviors, actions and images. It refers to a community in which people are interested in the same things, and it is a kind of self-

CINEJ Cinema Journal: Pattern of the Body Image in La Maison en Petit Cubes

Volume 3.1 (2013) | ISSN 2158-8724 (online) ｜ DOI 10.5195/cinej.2013.86 | http://cinej.pitt.edu 
identification under the group effect. These identification definitions depend on interactive communication between Japanese economy and watching anime. Hence, it is shaped under the economic system (Newitz 2009). Ueno argues that; people from outside of Japan are usually interested in manga, which is an element of Japanese subculture, and he claims that postfordist social environment of global actions has been effecting the Japanese animation (Ueno 2009). In 70's, 80's and 90's, Asiatic imagination power was growing up in Japan and Hong Kong. In the scene of modern arts, the indicators of modernization were Japan styles and designs. The most attractive one of these styles was Kawaii style, which refers to childlike, cute, charming, innocent, simple, gentle, delicate and sensitive personality (Kinsella 2009). A politic and economic culture was transferred to West through transmission of Kawaii images which were created and produced according to trends of time. The West was clearly under the effect of Japanization. It was the second Japanese triumph in the West especially in America. First of it was in the era of Art Nouveau in Europe. On the second Japanese artistic attack level; post-fordist economic system and cultural capitalism were effective. These effects had validity, not just for circulation of goods but the circulation of values through images like cinema in which images constitute a meaningful world. When the art movements is observed, national cinemas integrate with other arts, and to draw upon trends in modern art like German expressionism, Russian formalism. Italian futurism (Heise and Tudor 174). But, Japanese popular animated cinema has been producing media contents which integrate with commercial enterprises. Artistic interaction leaves its place to economic-cultural integration.

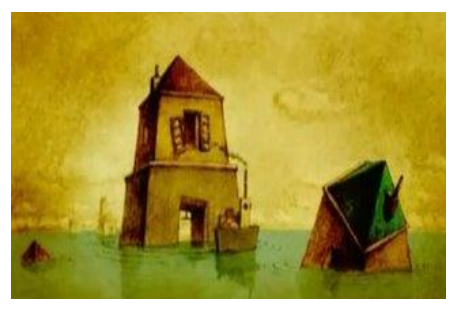

Fig. 1 The house of old man

According to Mescallado; the popular Japanese animated cinema depends on comics and this element is constituted by the mediation of local culture and thought (Mescallado 2009). On the contrary, classical Japanese animated cinema has not popular culture artifacts, and it follows the way of traditional Japanese art. Hence, technics of classical Japanese animated cinema depends on traditional arts with the dimension of content and form. The scenarios inspire of 
Japanese Kabuki Theatre and the forms inherit Japanese pictures and woodworks. Characteristics of classical Japanese animated cinema which is under the effect of traditional Japanese pictures are reflected and depicted in the animated artifacts which were produced by hand. When the history of animated cinema is followed, it can be seen that, classical animation depends on realistic components genetically, because, during the Second World War, it was used to produce propaganda and training films. In this respect, it was loaded with a mission beyond the fantastic world (Telotte 2006: 21-22). The classical Japanese animated cinema has been following this simple and genuine way while it is transmitting the reality.

The hidden and stationary landscape pictures of Ando Hiroshige who is the master of Japanese wood paintings were perceived as a gift which belongs to everyday life products by people. These artifacts were accepted as elitist productions through communication and increasing commercial activities of Japan with the West by famous artists like Edgar, Degas, Claude, Manet, and Vincent Van Gogh. European artists had been searching for new expression styles. Thus, Japanese artifacts were inspiration resource in their artworks for them (Hagen 2002: 352). According to art historian Klaus Berger; Japonism was the changing of point of view which depends on Copernican ideals. It pointed out of the end of Eurocentrist images and the beginning of the seeing, perceiving, and recording of the world on the new meaning phase (Hokenson 2004: 17). Artists exposed their vulnerable world expressions through Japan wood paintings style which requires delicate handwork. The figure which stands on the foreground is became clear from the blurred background to intense foreground by using of various degrees of shading and enlightenment. The most effective point in the depictions of expression of people's faces is to melt the intense lines and thus to reflect the tranquil atmosphere through silence and nebulous faces in the Japanese traditional pictures. This style depicts many things with a few lines. Natural organic vivid designs which inspire of nature establish a relationship between nature and artifacts in Japanese pictures. By these dimension, in the film, slowly disappearing images create an atmosphere in which simple and tranquil watching process is revealed. The main theme is emphasized in the center, and the strong expression level is formed as meaning. Hence, tranquil-delicate expression level is originated as linear. In this design style, the technique which uses the background as blur and misty, condenses the concentration. Artist depicts the main theme simply without rambling the main idea and message in the frame. This application makes strong the depth as physical and psychological; moreover, it references to "present-center" by releasing the "past -background" and "futureforeground. These characteristics of traditional Japanese picture present a poetic narrative expression in classical Japanese animated cinema. This kind of poetic narratives should be 
companionship with poetic visualization and vulnerable music. Repetition also possesses the quality that Agamben defines as the second transcendental condition of cinema: stoppage. This is where the difference lies between cinema and narrative; The relations between visualization and movement can be better appreciated by distinguishing between the specificity of film qua film, especially as it came to be known in the opening decade of the 20th century, and the earlier technologies of chronophotography and animated photography, often referred to as film before film. The latter's initial fixation on conceiving of matters in terms of immobile images to which movement could be added, rather than as 'movement-images' per se, is, for Deleuze, a matter of evolution from a set of initial technological conditions, paralleling the way life struggled to distinguish itself from matter: Agamben proposes: 'stoppage shows us that cinema is closer to poetry than prose'. Drawing an analogy with Paul Valéry's definition of poetry as 'a prolonged hesitation between sound and meaning (Clarke and Doel 2009: 112-114).

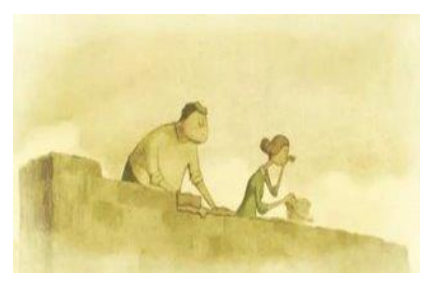

Fig. 2 A scene from past; the old man and his wife are building the first flat of their house

\section{The Body in Pain as a Tragedy Element}

According to Froma Zetilin; tragic Greek theatre, had showed the human body in unnatural pathos and suffer, when it was far away from integrity and power ideal, and tragedy had insisted on exhibiting the body in pain. But Western civilization refuses to accept this tragic pain as natural, either considers it as something which is open to social control or accepts it as part of conscious mental project (Sennet 1996). The body weaves a meaning network through the contact with the world. Merleau-Ponty argues that, there is a silence contact with things. The meaning, is constituted in the silence language of things before it was said in the perceptional life. The ancient world had encountered with a special life in the body of 
immortal one first time. This life, made itself double exception object through exclusion the both profane and religious forms of life from the real context. The original point of this life did not belong to the world of dead and shared a common living space with dead and private/privacy (Agamben 2004). This privacy causes the problem of body passivism in which reactions to others have deep roots. This passivist manner comes from Aristotle aesthetic and catharsis process in the film narratives. In this film, there is passive sentimentality instead of participation. In the cathartic expressions, there is always death, loneliness, yearning and longing. These emotions give birth to pain. Certainty of tragedy of loneliness in pain is found purely. Burden of existence is felt again in endeavor, trouble and suffer; moreover exist freedom produces this burden. The tragedy of loneliness is certainty of existence and materialism. Loneliness, is not tragic because of deprived of other, it is tragic because, it is closed in the captivity of identity, and it is material. Breaking the chains of material is breaking the certainty of hypostases. The loneliness is not appeared as deprivation of relationship with other. It depends on the artifacts of hypostase. Loneliness is unity of existence, to be something in the existence. Sorrow is alone because it is unique, and loneliness is required to exist. Then, loneliness is not only desperation and desertion but also proud, courage and sovereign [12]. The aim of the tragedy is to purify the soul from desires by rousing the fearful and sad emotions; it is called as Catharsis. As a result of this, the mission of whole tragic elements to create audiences who live cathartic experience in narration. Marilyn Fabe argues about film narrative techniques and examines and analyses the relationship between sound and film images to strengthen the catharsis effect which provokes the emotions [13]. This catharsis process is a way for expressing the narration in which human behaviors are reflected by the tragic activations. Kozin's approach called as crystal-film can be a model to understand the Kato's film in which both body and city are reflected. The choice of the name for the concept can be explained through the physical properties of mineral morphology: the structure of a crystal allows us to see how, with each turn of the crystal, what is opaque and virtual becomes luminous and actual. This reversibility makes all sorts of binaries coalesce, taking us beyond anthropological structuralism with its staple distinctions: 'hard' and 'soft', 'saying' and 'said', 'past' and 'future', 'here' and 'there'. Our thoughts become matter, while matter becomes an object of our thoughts. The 'crystal-film' is, therefore, the kind of film that exposes the relations between what is being reflected and the act of reflecting, or to put it in phenomenological terms, the 'given' and 'givenness (Kozin 2009: 109). 


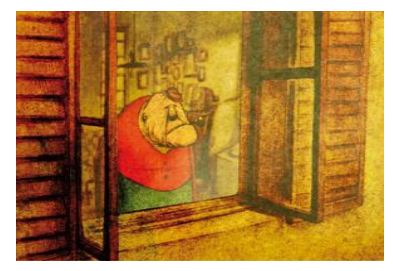

Fig 3 The room of old man

Many modernists were convinced that animation was the true telos of film, because it could emancipate the new medium from the pitfalls of theatrics and realistic representation. Critical theorists simultaneously politicized these animated tropes of aesthetic emancipation, linking them to the social and technological forces that were both unleashed and constrained within capitalist modernity. With a bit of help from modernism and critical theory, the transfixed highbrow viewer of early animation could easily imagine for a moment that it was poised to transform the popular surface of the emergent celluloid medium with a new and subversive aesthetic: an aesthetic of fantasy and freedom (Connell 2004:139). Kato's film has a narration which depends on tragedy. This narration has some important tragedy points which is shaped on the direction of story skeleton on which pain and coincidence elements are used. The spirit of the film is story (mythos). The Anagronisis element of a tragic narration is a process which means remembering the forgotten events, and it is a passing from ignorance to knowledge or from awareness to be aware of something. The old man's Anagronisis is to dive under the water in which his house rises up. This diving metaphor which symbolizes the journey to the past reminds of his family and past. Hence, he finds himself more powerful to survive in the city which is covered with waters. Pathos element is a grievous event. In the film, the journey of the old man to his past under the water is pathos. Tragedy imitates of good characters who are better than average people. There is a person who is activist as drontas element in a tragedy. This film is a kind of loneliness symphony in which good-tempered old man lives as a drontas character. The mimesis of life should be full of happiness and catastrophes. Because of this, actions and purposes are important. The old man's life and his happy days with his family constitute this mimesis element. The other tragedy element of the film is periphetie which means the destiny changing. Periphetic point is the falling moment of the pipe to the water. In the beginning, the old man looks for a new pipe but he doesn't satisfy with the other pipes. Thus, he decides to find his own pipe which will be a transporter to his past life. This event leads to an unexpected journey to the bottom of the water and the tragic one reveals. 


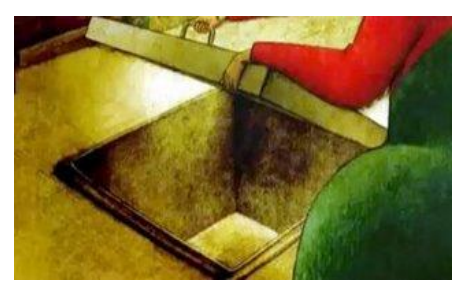

Fig 4 The old man opens the damper

In ancient times, a deep trace was being opened to make a holly border which was called as pomerium. Kato creates a kind of pomerium which causes a periphetic action. The damper is a pomerium in which old man's pipe disappeared, and it is a way to reach to the other flats of house under the water.

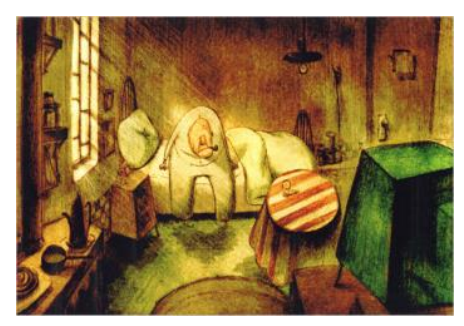

Fig 5 The flat of old man

\section{The Milieu as an Integration with Body-City}

People play the roles and thus they generate the structure. People are like the magnetic poles. They underline generators of the structure. They are a necessary foundation on which the possibility of social structures depends (Harré 2002:114). This social structure is an extension of body image which is shaped under the effect of socialization. The statue of the body is a culture fact. The organizing style of relations with the body reflects the organizing style with things and social relations in every culture. The general statue of private property is applied both to the body as part of social practice and to the presentation of this practice in mind in a capitalist society (Baudrillard 2008) Gibson argues about the structure and the text of the environment. It is a necessary determinant of what is perceived. Spatial perception is active observer moving in dynamic world (Rodaway 1994:19). Bodies, temples and cities, was expressing the principles of a society which had well organized lined in Roman period (Sennet 1996). In Kato's film, the old man as an expressive medium, has a life struggle by narrowing 
his living space which remembers the passing of time. He carries his items to his new flat of his building and to the new phase of his life. Every flat refers to a new life experience. The every flat covered with the water is his past life. The rising of the building is ascending to the sky. Space narrows; time passes, body grows old.

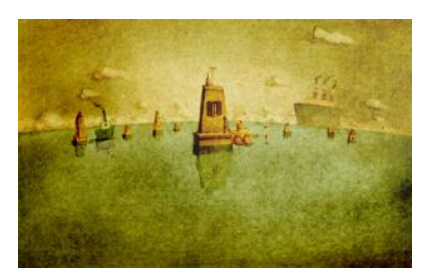

Fig 6 The city in which the old man lives

Milieu is a context in which reality is reproduced and perceived in modernism. It is perceived and defined not only through its emptiness but also through conceptual construction. For this reason, modernism considers the milieu both as plastic, and it knows that a milieu is a fiction which can be devastated and can be removed (Kahraman 2005: 27). Elizabeth Grosz puts forward two basic approaches which examines the relationship between milieu and body. In first of these, body-milieu relationship has a "de facto" reality and integrity, and she defines the city as an extension, reflection and product of the body. In her second proposition, she sets up a parallelism or isomorphism relationship. Elements of the city are like organs of the body. The common acceptable point of two approaches is the city which exists as simulacrum of body, but on the second phase, the body is transformed, urbanized, citified and perceived as metropolitan body. These elements of body lead to an architectural reality in which bodies breathe as a social actors. Architecture is an intervention in mentality map through its milieu. The relationship of milieu with body, memory, identity and their pre-determined hierarchic definitions are affected by this intervention (Kahraman 2005: 235). In Kato's film, the milieu in which body lives, is symbolized by water. The past of the old man is appeared under the water. It comprises conceals and preserves. The milieu is always open to be discovered in the concreteness of necessity. Human should work by his hand to overcome it (Levinas 1990). In the light of Levinas's ideas; the old man works hardly to overcome life struggle under the condition of rising water. There is an extremist working situation which aims to survive. It can be seen an analogy between old man's house and Babel tower. Both of them represent to reach the God. The city design strengthens the tragedy elements as decoration. The city design covering with water which leads to subconscious is used to realize anachronistic aim. The old 
and exhausted body of the old man integrates with ruined city after an ecological catastrophe. People cannot be seen except a salesman in the milieu. Water which separates the buildings prevents from communication facilities between people and creates a social and real distance in the milieu. Modernity is to us as water to fish. The invisibility of modernity to be both fascinating and disconcerting for the water around us modern fish is becoming increasingly cloudy (Spretnak 1999: 217). It has been known that, Virilio argues about the city which was strengthened by city walls. The city was trying to regulate the momentum and circulation of city masses. Portable and accelerating guns may cause the environment catastrophes. People began to wander for setting up. While the cities were changing in velocity, people tried to adapt to change. These changes were creating a speed fact but there is no dromokratic intelligence which is used as an attack to the world or to the nature of human through the world (Virilio 2006). On the contrary to this situation, it can be observed that the old man never thinks of moving to somewhere else. He insists on living in his own place. Thus, he prefers feeling his own tragedy resisting to move not to forget his past.

\section{Conclusion}

In this study, Kunio Kato's film La Maison en Petits Cubes was examined and analyzed according to the content and visual design. The visual design of the film is based on traditional Japanese pictures in which basic characters of national Japanese art is found. The film is an extraordinary production by the dimension of except for popular Japanese animated films which have the big market in the world. Although Kunio Kato is a young artist, their works show his responsible, sensitive, delicate and artistic behavior. Because of the flood, the life struggle of an individual attracts attention to an ecological catastrophe. The artist reaches to universal film language using his national arts which include the Japanese pictures. According to the second determination, the scenario aesthetic of the film depends on Aristotle's aesthetic which expresses the tragic narrations. Instead of using the alienation, the artist prefers participator, sentimental, thought provoking expressions. This cathartic film integrates with extraordinary visual design which is not preferred in the era of digital arts. The film tells that, even though this information era requires the $3 \mathrm{D}$ animated films to satisfy the consumers, 2D animated films have still important influence on spectators. The inspiring element of the film can be seen as the geographical loneliness, isolation and distance of Japan from continents in the oceanic waters. The film La Maison en Petits Cubes has crucial 
importance to stimulate and interrogate the self that is effected by new communication technologies, exists in the digital space, has cybernetic feelings and alternative digital lifestyles like "second life" in the dromologic conditions of the societies.

\section{REFERENCES}

Agamben, G. (2004). The Open: Man and Animal.Stanford University Press.

Baudrillard, J. (2008) Perfect Crime. London: Verso.

Clarke, D. B. and M. A. Doel (2007) "Shooting space, tracking time: the city from animated photography to vernacular relativity", Cultural Geographies, vol. 14, no. 4: 589-609.

Connell, M. F. (2004) "Book Review of Esther Leslie Hollywood flatlands: animation, critical theory and the Avant-Garde" Theory, Culture \& Society, vol. 21, No 2: 139-142.

Fabe, M. ((2005) "Book review of Closely watched films: An introduction to the art of narrative film technique”, European Journal of Communication, vol. 20, No 1 p.144.

Hagen, R. M. (2002) Masterpieces in detail; old masters in detail, Bonn: Taschen Verlag.

Harré, R. (2002). "Social structure and social change: social reality and the myth of social structure", European Journal of Social Theory, vol 5, pp.111-123.

Heise, T. and A. Tudor (2007) "Constructing (Film) art: Bourdieu's field model in a comparative context", Cultural Sociology, vol. 1, no. 2. 165-187.

Hokenson, J.W. (2004) Japan, France and East-West aesthetics; French literature 18672000, New Jersey, Fairleigh Dickinson University Press.

Kahraman, H. B. (2005) Sanatsal gerçeklikler, olgular ve öteleri, İstanbul, Agora.

Kinsella S. (2009) Japanization of European youth, 12 May Available: http://www.kinsellaresearch.com/Japanization.html

Kozin, A. (2009) "The appearing memory: Gilles Deleuze and Andrey Tarkovsky on `crystalimage"”, Memory Studies, vol. 2: 103-117.

Levinas, E. (1990) Time and the Other. Duquesne University Press.

Mescallado, R. (2009) "Otaku nation, science fiction studies", 12 May Available: http://www.depauw.edu/sfs/review_essays/mescallado80.html

Newitz, A. (2009), Anime Otaku: Japanese Animation Fans Outside Japan, 12 May Available: http://bad.eserver.org/issues/1994/13/newitz.html, 12.05.2009

Rodaway, P. (1994) Sensuous Geographies: Body, Sense and Place, London: Routledge. 
Sennet, R. (1996) Flesh and Stone: The Body and the City in Western Civilization, New York: W. W. Norton.

Spretnak, C. (1999) The Resurgence of the Real Body: Nature and Place in a Hypermodern World. London: Routledge.

Telotte, J. P. (2006) “Ub Iwerks' (Multi)Plain Cinema”, Animation, vol. 1, no 1: .9- 24.

Ueno, T. (2009), Japanimation and techno-orientalism, 12 May Available: http://www.t0.or.at/ueno/japan.html

Virilio, P. (2006). Speend and Politics. Semiotexte. 